\title{
Activity-Inactivity Patterns, Screen Time, and Physical Activity: The Association with Overweight, Central Obesity and Muscle Strength in Polish Teenagers. Report from the ABC of Healthy Eating Study
}

\author{
Magdalena Górnicka ${ }^{1}\left(\mathbb{D}\right.$, Jadwiga Hamulka ${ }^{1, *} \mathbb{}$, Lidia Wadolowska ${ }^{2}$, \\ Joanna Kowalkowska ${ }^{2}{ }^{\circledR 0}$, Eliza Kostyra ${ }^{3}{ }^{\circledR}$, Marzena Tomaszewska ${ }^{4}$, Jan Czeczelewski ${ }^{5}$ \\ and Monika Bronkowska 6 (D) \\ 1 Department of Human Nutrition, Institute of Human Nutrition Sciences, Warsaw University of Life \\ Sciences (SGGW-WULS), Nowoursynowska Str 159C, 02-776 Warsaw, Poland; \\ magdalena_gornicka@sggw.edu.pl \\ 2 Department of Human Nutrition, Faculty of Food Sciences, University of Warmia and Mazury in Olsztyn, \\ Pl. Cieszynski 1, 10-718 Olsztyn, Poland; lidia.wadolowska@uwm.edu.pl (L.W.); \\ joanna.kowalkowska@uwm.edu.pl (J.K.) \\ 3 Department of Functional and Organic Food, Institute of Human Nutrition Sciences, Warsaw University of \\ Life Sciences (SGGW-WULS), Nowoursynowska Str 159C, 02-776 Warsaw, Poland; \\ eliza_kostyra@sggw.edu.pl \\ 4 Department of Food Gastronomy and Food Hygiene, Institute of Human Nutrition Sciences, Warsaw \\ University of Life Sciences (SGGW-WULS), Nowoursynowska Str 159C, 02-776 Warsaw, Poland; \\ marzena_tomaszewska@sggw.edu.pl \\ 5 Faculty of Physical Education and Health in Biała Podlaska, Josef Piłsudski University of Physical Education \\ in Warsaw, Akademicka Str 2., 21-500 Biała Podlaska, Poland; jan.czeczelewski@awf-bp.edu.pl \\ 6 Department of Human Nutrition, Faculty of Biotechnology and Food Science, Wroclaw University of \\ Environmental and Life Sciences, Chelmońskiego Str 37, 51-630 Wroclaw, Poland; \\ monika.bronkowska@upwr.edu.pl \\ * Correspondence: jadwiga_hamulka@sggw.edu.pl; Tel.: +48-22-593-71-12
}

Received: 10 September 2020; Accepted: 22 October 2020; Published: 26 October 2020

check for updates

\begin{abstract}
Today, the time spent actively is increasingly being replaced by screen-based media, although in some teenagers, a high level of physical activity (PA) and longer time spent in front of a screen (screen time, ST) may coexist as a mixed behavioral pattern. This study aimed to examine the association of the pattern created as activity (low/high ST with high PA) and inactivity patterns (low/high ST with low PA) with overweight, central obesity, and muscle strength in Polish teenagers taking into consideration socioeconomic and demographic factors. Cross-sectional data were collected from elementary school children $(n=1567)$, aged 11-13 years. Height, weight, waist circumference, and handgrip strength were measured. Body mass index (BMI) was calculated as the overweight measure, and the waist-to-height ratio (WHtR) was calculated as the central obesity measure. Data on ST, PA, socioeconomic status, demographics, and nutrition knowledge were collected by a questionnaire. Activity-inactivity patterns were defined by an a priori approach. Multivariate logistic regression modelling was applied. The most active pattern (lowST-highPA) was found in $17 \%$ of the total sample. Teenagers with the most inactive pattern (highST-lowPA) had over four times higher chance of general overweight. No association between WHtR $\geq 0.5$ and highST-highPA pattern was found. Higher muscle strength ( $>1 \mathrm{SD}$ ) was associated only with high physical activity. Urban residence or lower socioeconomic status increased adherence to the most inactive pattern. From a public health perspective, implementing interventions promoting active
\end{abstract}


patterns in 11-13-year-old teenagers is important for obesity prevention and enhanced physical fitness, especially in girls, teenagers living in urban areas, and from families with lower socio-economic status.

Keywords: screen time; physical activity; activity pattern; inactivity pattern; adiposity; BMI; WHtR; muscle strength; Polish teenagers

\section{Introduction}

Currently, obesity, not only in adults but also in children and adolescents, is one of the most serious global problems affecting every country in the world [1]. Nearly one out of six children is overweight or obese in Organisation for Economic Cooperation and Development (OECD) countries (of which Poland has been a member since 1996). In the last four decades, the prevalence rates for obesity have risen ten times and it is assumed that the current trend continues [2]. In Polish children, both general and abdominal obesity have increased significantly over the past 50 years, with a tendency toward central obesity [3].

The increase in obesity occurrence is associated with technological progress and socio-economic development, which has created the so-called "obesogenic environment". It is well-documented that the increase in obesity occurrence, regardless of the region of the world [4-8], is associated with more sedentary behaviors causing lower energy expenditure and an increase in unhealthy dietary behaviors, such as the consumption of sugar-sweetened beverages and discretionary snacks $[9,10]$. In recent years, we have seen the increase in access to electronic equipment, including televisions, computers, smartphones, and other mobile devices. This has resulted in a long time spent sitting in front of a screen (screen time, ST), also among children [8]. Furthermore, technological changes in transport (more frequent use of a car, bus, tram, metro/subway/underground), household equipment, and new forms of spending free time with the use of screen devices, has reduced body energy expenditure [11]. Hence, prolonged screen time combined with sitting time may decrease time spent in physical activity (PA), e.g., in the open air or in a sports hall, which could increase the occurrence of obesity and other non-communicable diseases, including diabetes type 2, hypertension, dyslipidaemia or musculoskeletal disorders (especially osteoarthritis), and worsening mental health and social well-being $[4,12,13]$.

In turn, physical activity plays a protective role against excessive body fat mass $[14,15]$ and positively correlates with health indicators such as health status, self-image, quality of life and family and peer relationship [16], as well as healthy child development $[17,18]$. Moreover, vigorous, systematic PA determines muscle strength [19] and is positively associated with muscular fitness [20] and with muscle mass [21]. Unfortunately, research from recent years suggests that the recommended level of physical activity was not achieved by $80 \%$ of children and teenagers in 105 countries worldwide [17].

According to the World Health Organization (WHO) [22], as well as Polish recommendations [23], children and adolescents should be physically active for at least one hour of moderate to vigorous PA per day and vigorous-intensity PA at least three times per week. Also, Polish recommendations for children and adolescents regarding ST, including television watching, using a computer, etc. [23], are consistent with the worldwide applied recommendations of the American Academy of Pediatrics (AAP) [24]. Today, the time spent actively is increasingly being replaced by screen-based media, although in some teenagers, a high level of physical activity (PA) and longer time spent before a screen (screen time, ST) may coexist as a mixed behavioral pattern [25].

Since scientific evidence appears inconclusive and there are no studies in the Polish population of this group of children, the current study aimed to examine the association of the pattern created as activity (low/high ST with high PA) and inactivity patterns (low/high ST with low PA) with overweight, central obesity, and muscle strength in Polish teenagers taking into consideration socioeconomic and demographic factors. It was hypothesized that inactivity patterns can increase the occurrence of obesity and low muscle strength in Polish teenagers, and it can be associated with socio-demographic factors. 


\section{Materials and Methods}

\subsection{Ethical Approval}

The study was approved by the Bioethics Committee of the Faculty of Medical Sciences, the University of Warmia and Mazury in Olsztyn, on 17 June 2010 (resolution no. 20/2010) and conducted in accordance with the principles of the Declaration of Helsinki. Informed written consent was obtained from parents or legal guardians of teenagers.

\subsection{Study Design and Participants}

To achieve the proposed objectives, a cross-sectional study was conducted of the "ABC of Healthy Eating" national multicenter project. Data were collected (in 2015-2016) by researchers from eight academic centers in Poland. Children were recruited among students aged 11-13 years in 35 elementary schools covering the entire territory of Poland. A convenient sample selection was applied. More details on the study design, methods, sample selection (collection) and early findings of the above-mentioned study were described in previous papers [26-28] and presented in a flowchart of this study (Figure 1). Finally, the study included 1567 teenagers aged $11-13$ years-760 boys (48.5\%) and 807 girls (51.5\%).

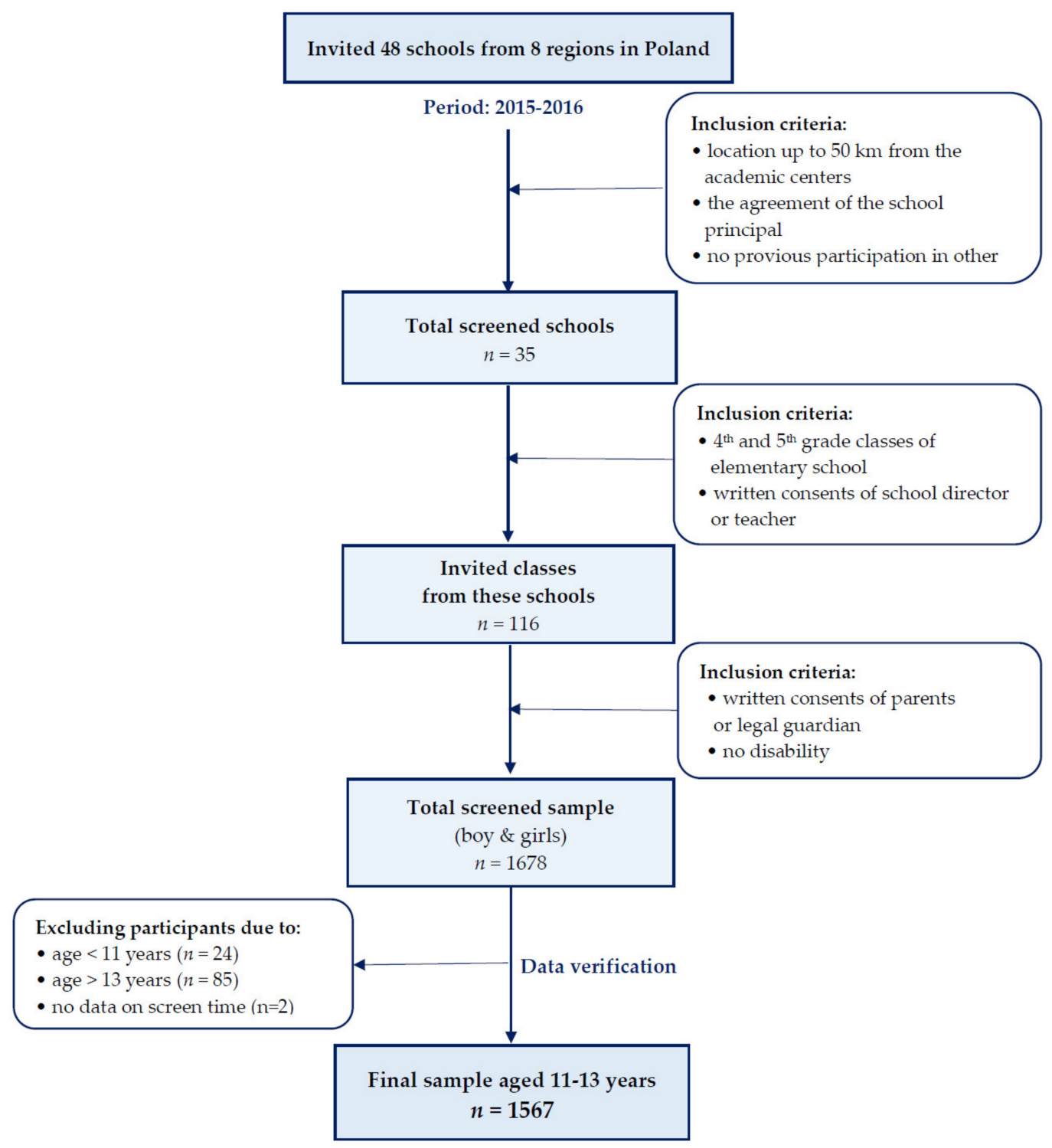

Figure 1. Flowchart of study sample collection. 
Data related to socioeconomic and demographic factors, nutrition knowledge and lifestyle characteristics, including usual frequency consumption for breakfast, school meal, and nine food items, as well as screen time and total physical activity, were collected with a short-form of a multi-component questionnaire (acronym: SF-FFQ4PolishChildren) developed by Kowalkowska, Wadolowska, and Hamulka for the "ABC of Healthy Eating" project. A reproducibility procedure of the SF-FFQ4PolishChildren (short form of FFQ) and more details on this questionnaire and study were described previously [29].

\subsection{Measures}

In this study, given that ST and PA are interrelated, activity-inactivity patterns were defined by an a priori approach using data on ST and physical PA for integrative classification.

\subsubsection{Screen Time (ST)}

Screen time was assessed using the question: How much time do you spend watching TV or in front of a computer on an average day of the week? It was explained to participants that all time spent in a sedentary manner should be considered; however, time spent with smartphones (e.g., while walking) should not be considered. The respondents chose one of six categories (hours/day): $<2 ; 2$ to $<4 ; 4$ to $<6 ; 6$ to $<8 ; 8$ to $<10 ; \geq 10$. Response categories of ST were combined into three categories (h/day): $<2 ; 2$ to $4 ; \geq 4$. Considering the recommended daily maximum of two hours of sedentary screen time for children and teenagers as a reference [23,24,30,31], ST $<2 \mathrm{~h} /$ day was defined as low, and $\geq 4 \mathrm{~h} /$ day was defined as high.

\subsubsection{Physical Activity (PA)}

PA was assessed using two questions about the level of PA at school: How would you describe your physical activity in school, and during leisure time, how would you describe your physical activity during your time off (after classes, on weekends)? The respondents chose one of three categories describing their physical activity at school and during leisure time: low, moderate, or vigorous. Examples for each category of PA were provided to choose from. More details on this questionnaire part have been provided in previous papers [26,29]. Finally, after combining categories of responses, three total PA levels-low PA, moderate PA, and high PA—-were created [26].

\subsubsection{Activity-Inactivity Patterns}

Patterns were defined by an a priori approach using previously developed categories for ST and PA (Table 1), and based on a definition of inactivity as an insufficient level of activity [32]. For further analysis, four main patterns were selected: highST-lowPA (the most inactive pattern), lowST-lowPA, highST-highPA, and lowST-highPA (the most active pattern). Each participant was allocated to one of four patterns. All categories with moderate ST and/or moderate PA were combined as "other" but were not included in further analysis. Based on recommendations regarding PA and ST, the lowST-highPA pattern was assumed as a reference [33].

Table 1. Activity-inactivity patterns categorized as screen time (ST) or physical activity (PA).

\begin{tabular}{ccccc}
\hline \multirow{2}{*}{ Physical Activity } & \multicolumn{3}{c}{ Screen Time } & \multirow{2}{*}{ Patterns * } \\
\cline { 2 - 4 } & Low & Moderate & High & inactive \\
low & lowST-lowPA & other & THE MOST INACTIVE PATTERN & - \\
moderate & other & other & highST-highPA & active \\
high & lowST-highPA & other & &
\end{tabular}

* the main patterns taken into account in further analysis are marked with the bold fonts. 


\subsubsection{Anthropometric Data}

Height, weight, waist circumference, and handgrip strength were directly measured by qualified researchers during an in-school visit according to International Standards for Anthropometric Assessment [34]. Height (to the nearest $0.1 \mathrm{~cm}$ ) was measured using a SECA 220 portable telescopic measuring rod (Hamburg, Germany). Weight (to the nearest $0.1 \mathrm{~kg}$ ) was measured using an electronic digital scale (SECA 799, Hamburg, Germany) and waist circumference by a stretch-resistant tape that provides a constant $100 \mathrm{~g}$ tension (SECA 201, Hamburg, Germany). All measurements were performed under strictly standardized conditions (between 08:00 and 12:00) using the same device to avoid inter-observer and inter-device variability and after explaining the procedure to each child. Measurements were taken twice in light clothing and without shoes, and the averages were calculated.

To identify general overweight, gender-and age-related body mass index (BMI) was applied with cut-offs as BMI $\geq 25 \mathrm{~kg} / \mathrm{m}^{2}$, according to the International Obesity Task Force (IOTF) [35]. To identify central obesity, measurement of the waist-to-height ratio (WHtR) with a cut-off point of 0.5 was used [36].

Handgrip strength $(\mathrm{kg})$ was measured twice for the dominant hand, according to the respondent's declaration (right or left), using a hydraulic hand dynamometer (manufacturer; SAEHAN Corporation, Masan, Korea). For further analyses, the average value of two measurements was taken. The z-score of handgrip strength (z-HGS) was calculated based on the authors' own database to achieve a mean equal to 0 and standard deviation (SD) equal to 1 . Based on variable distribution, the z-score was categorized as follows: <-1 SD as lower muscle strength; -1 to 1 SD as normal; and $>1$ SD as higher muscle strength [26].

\subsubsection{Socioeconomic and Demographic Data}

The demographic predictors of activity-inactivity patterns included gender, age, and residence (rural or urban). The socioeconomic status was determined using the Family Affluence Scale (FAS) and included four questions (about the family car, one's own bedroom, family holidays, and the number of computers/laptops/tablets) prepared by the Polish team in the international HBSC study [37]. Points were assigned to each answer and summed up for each respondent (range 0-7). Based on quartile distribution, the respondents were divided into three FAS categories labelled as low (0-4 points; $<25$ th quartiles), moderate (5-6 points), and high (7 points; $\geq 75$ th quartiles).

\subsubsection{Nutrition Knowledge Score}

This score was determined based on eighteen questions, developed by Whati et al. [38] and adapted to Polish conditions and education [26]. The correct answer scored 1 point, and wrong or

"I don't know" answers or missing answers scored 0 points. After summing up (0-18 points) nutrition knowledge score was calculated for each participant.

\subsection{Statistical Analysis}

Variables were presented as a sample percentage (\%) or mean and standard deviation. The differences between groups were verified by $\mathrm{Chi}^{2}$ Pearson test for categorical variables or Kruskal-Wallis test for continuous variables.

A multivariate logistic regression modelling was applied to assess:

1. The chance to fall in the category of central obesity or overweight or higher muscle strength. Activity (highST-highPA) and inactivity patterns (lowST-lowPA, highST-lowPA) were used as predictors, while the lowST-highPA pattern was used as a reference.

2. The adherence to activity-inactivity patterns by socioeconomic and demographic factors, in respect to a referent lowST-highPA pattern, the following categorical variables were used as predictors (independent variables): gender (girls, reference: boys), age (12 or 13 years, reference: 11 years), residence (urban, reference: rural), and Family Affluence Scale (moderate or high, reference: low). 
The odds ratios (ORs) and 95\% confidence interval (95\% CI) were calculated. The ORs were adjusted $\left(\mathrm{OR}_{\mathrm{A}}\right)$ for gender, age (years), residence (two categories), FAS (points), and nutrition knowledge score (in points, excluding the modelled variable from the confounders set, respectively). The significance of ORs was assessed by Wald's statistics. For all tests, $p<0.05$ was considered significant. All statistical analyses were performed using STATISTICA software (version 12.0 PL; StatSoft Inc., Tulsa, OK, USA; StatSoft, Krakow, Poland).

\section{Results}

The demographic and socioeconomic characteristics of the study population are presented in Table 2. The sample consisted of $48 \%$ boys and $52 \%$ girls. Most of the teenagers were aged 12 years $(74 \%)$, had urban residence $(60 \%)$ and about half came from families with moderate FAS. Overall, $46 \%$ of teenagers declared ST $<2 \mathrm{~h} /$ day and $31 \%$ indicated high PA (Table 2 ). Over $42 \%$ of boys and $50 \%$ of girls reported ST $<2 \mathrm{~h} /$ day, while $23 \%$ and $16 \%$ of boys and girls, respectively, reported high ST ( $\geq 4 \mathrm{~h} /$ day). High PA was found in $37 \%$ of boys and $26 \%$ of girls (Table 2). About $46 \%$ of teenagers reported vigorous PA at school and 50\% declared vigorous PA at leisure time (Table S1). More boys than girls had ST $\geq 4 \mathrm{~h} /$ day (Table 2) and high PA, vigorous PA at school and at leisure time (Table S2). Over 21\% of teenagers with urban residence and $16 \%$ of with rural reported ST $\geq 4 \mathrm{~h} /$ day. A lower percentage of teenagers with high FAS compared with low FAS declared ST $\geq 4 \mathrm{~h} /$ day, $(17 \%$ vs. $23 \%)$, low PA in total ( $5 \%$ vs. $15 \%$ ) (Table 2$)$, low PA at school ( $4 \%$ vs. $8 \%$ ) or at leisure time $(6 \%$ vs. $15 \%)$ (Table S1). Only about $17 \%$ of teenagers represented the most active pattern (lowST-highPA), which included more boys ( $19 \%$ vs. $15 \%$ of girls), teenagers with high FAS ( $20 \%$ vs. $12 \%$ of with low FAS), and with a higher value of Nutrition Knowledge Score (Table 3).

Overweight was found in $25 \%$ of teenagers, while central obesity in $12 \%$ (Table 4 ). Nearly $40 \%$ of teenagers with highST-lowPA pattern and 34\% with a lowST-lowPA pattern were overweight. The percentage of teenagers with central obesity $(23.4 \%)$ was the highest in teenagers with a lowST-lowPA pattern, while the lowest $(4 \%)$ was found in teenagers with the most active pattern (lowST-hihg PA). Over $32 \%$ of teenagers with ST $\geq 4 \mathrm{~h} /$ day and $42 \%$ with low PA were overweight, while $18 \%$ and $22 \%$, respectively, had central obesity (Table 4 ). Only about $8 \%$ of teenagers with low PA had higher muscle strength, compared with $17 \%$ with high PA (Table 4 ). 
Table 2. Characteristics of participants ( $\% \mathrm{~N}$ or mean $\pm \mathrm{SD})$.

\begin{tabular}{|c|c|c|c|c|c|c|c|c|c|c|}
\hline \multirow{2}{*}{ Variables } & \multicolumn{2}{|c|}{ Total Sample } & \multicolumn{3}{|c|}{ Screen Time (h/day) } & \multirow{2}{*}{$p$-Value ${ }^{2}$} & \multicolumn{3}{|c|}{ Physical Activity } & \multirow{2}{*}{$p$-Value } \\
\hline & $\mathbf{N}$ & $\%$ & $<2$ & 2 to $<4$ & $\geq 4$ & & Low & Moderate & High & \\
\hline Sample size ${ }^{1}$ & 1567 & & 726 & 539 & 302 & & 154 & 923 & 490 & \\
\hline Sample percentage & & 100.0 & 46.3 & 34.4 & 19.3 & & 9.8 & 58.9 & 31.3 & \\
\hline \multicolumn{11}{|l|}{ Gender } \\
\hline boys & 758 & 48.4 & 42.1 & 35.2 & 22.7 & \multirow[b]{2}{*}{0.0006} & 10.0 & 53.3 & 36.7 & \multirow{2}{*}{$<0.0001$} \\
\hline girls & 809 & 51.6 & 50.3 & 33.6 & 16.1 & & 9.5 & 64.2 & 26.3 & \\
\hline \multicolumn{11}{|l|}{ Age (years) } \\
\hline 11 & 260 & 16.6 & 47.3 & 37.3 & 15.4 & \multirow{3}{*}{0.4753} & 8.4 & 58.2 & 33.3 & \multirow{3}{*}{0.3168} \\
\hline 12 & 1153 & 73.6 & 46.3 & 33.8 & 19.9 & & 10.0 & 58.2 & 31.8 & \\
\hline 13 & 154 & 9.8 & 44.8 & 33.8 & 21.4 & & 10.5 & 65.4 & 24.2 & \\
\hline \multicolumn{11}{|l|}{ Residence } \\
\hline rural & 631 & 40.3 & 46.8 & 37.4 & 15.8 & \multirow{2}{*}{0.0099} & 7.9 & 58.2 & 33.9 & \multirow{2}{*}{0.0507} \\
\hline urban & 936 & 59.7 & 46.0 & 32.4 & 21.6 & & 11.0 & 59.4 & 29.6 & \\
\hline \multicolumn{11}{|c|}{ Family Affluence Scale (categories) } \\
\hline low & 381 & 24.3 & 40.9 & 36.5 & 22.6 & \multirow{3}{*}{0.0293} & 15.0 & 58.8 & 26.2 & \multirow{3}{*}{$<0.0001$} \\
\hline moderate & 781 & 49.9 & 49.7 & 31.6 & 18.7 & & 9.5 & 59.2 & 31.3 & \\
\hline high & 403 & 25.8 & 45.2 & 37.5 & 17.4 & & 5.4 & 58.2 & 36.4 & \\
\hline \multicolumn{11}{|c|}{ Family Affluence Scale (0-7 points) } \\
\hline Mean \pm SD & 1565 & 99.9 & $5.4 \pm 1.5$ & $5.4 \pm 1.5$ & $5.2 \pm 1.6$ & 0.1208 & $4.7 \pm 1.8$ & $5.4 \pm 1.5$ & $5.5 \pm 1.4$ & $<0.0001$ \\
\hline \multicolumn{11}{|c|}{ Nutrition Knowledge Score (0-18 points) } \\
\hline Mean \pm SD & 1566 & 99.9 & $6.2 \pm 2.8$ & $6.2 \pm 2.8$ & $5.5 \pm 2.8$ & 0.0003 & $5.8 \pm 2.9$ & $6.0 \pm 2.8$ & $6.3 \pm 2.9$ & 0.1619 \\
\hline
\end{tabular}

${ }^{1}$ Sample size may vary in variables due to missing data; ${ }^{2}$ significance level of $\mathrm{Chi}^{2}$ Pearson test for categorical variables or Kruskal-Wallis test for continuous variables. 
Table 3. Activity-inactivity patterns in participants by variables ( $\% \mathrm{~N}$ or mean $\pm \mathrm{SD})$.

\begin{tabular}{|c|c|c|c|c|c|c|}
\hline \multirow{2}{*}{ Variables } & \multirow{2}{*}{$n$} & \multicolumn{4}{|c|}{ Activity-Inactivity Patterns ( $=1567)$} & \multirow{2}{*}{$p$-Value ${ }^{1}$} \\
\hline & & LowST-HighPA & HighST-HighPA & LowST-LowPA & HighST-LowPA & \\
\hline $\mathrm{N}$ & 438 & 261 & 76 & 50 & 51 & \\
\hline$\% \mathrm{~N}$ & 28.0 & 16.7 & 4.8 & 3.2 & 3.3 & \\
\hline \multicolumn{7}{|l|}{ Gender } \\
\hline boys & 241 & 18.6 & 7.1 & 2.8 & 3.3 & \multirow{2}{*}{0.0002} \\
\hline girls & 197 & 14.9 & 2.7 & 3.6 & 3.2 & \\
\hline \multicolumn{7}{|l|}{ Age (years) } \\
\hline 13 & 38 & 12.4 & 6.5 & 2.6 & 3.9 & 0.6596 \\
\hline \multicolumn{7}{|l|}{ Residence } \\
\hline rural & 171 & 17.3 & 5.1 & 3.0 & 1.7 & \multirow[b]{2}{*}{0.0914} \\
\hline urban & 267 & 16.3 & 4.7 & 3.3 & 4.3 & \\
\hline \multicolumn{7}{|c|}{ Family Affluence Scale (categories) } \\
\hline low & 104 & 11.8 & 4.5 & 5.0 & 6.3 & $<0.0001$ \\
\hline \multicolumn{7}{|c|}{ Nutrition Knowledge Score (0-18 points) } \\
\hline Mean \pm SD & 438 & $6.4 \pm 2.8$ & $5.4 \pm 2.6$ & $6.2 \pm 3.0$ & $5.3 \pm 2.8$ & 0.0016 \\
\hline
\end{tabular}

$\mathrm{N}$-the sample size; $n$-the subsample number; ${ }^{1}$ significance level of $\mathrm{Chi}^{2}$ Pearson test for categorical variables or Kruskal-Wallis test for continuous variables; ST—-screen time, PA-physical activity. 
Table 4. Distributions (\%) of body mass index (BMI) category, central obesity and muscle strength by activity-inactivity patterns, screen time (ST), and physical activity (PA).

\begin{tabular}{|c|c|c|c|c|c|c|c|c|c|c|}
\hline \multirow{2}{*}{ Variables } & \multicolumn{3}{|c|}{ Gender-Age-Related-BMI $^{2}$} & \multirow{2}{*}{$p$-Value $^{5}$} & \multirow{2}{*}{ Central Obesity ${ }^{3}$} & \multirow{2}{*}{$p$-Value } & \multicolumn{3}{|c|}{ Muscle Strength $^{4}$} & \multirow{2}{*}{$p$-Value } \\
\hline & Underweight & Normal Weight & Overweight & & & & Lower & Normal & Higher & \\
\hline Sample size ${ }^{1}$ & 145 & 980 & 368 & & 182 & & 147 & 892 & 148 & \\
\hline Sample percentage & 9.7 & 65.6 & 24.6 & & 12.2 & & 12.4 & 75.1 & 12.5 & \\
\hline \multicolumn{11}{|c|}{ Activity-inactivity patterns } \\
\hline lowST-highPA & 11.2 & 77.2 & 11.6 & \multirow{4}{*}{$<0.0001$} & 4.4 & \multirow{4}{*}{$<0.0001$} & 9.8 & 77.8 & 12.4 & \multirow{4}{*}{0.3367} \\
\hline highST-highPA & 8.2 & 68.5 & 23.3 & & 8.2 & & 5.3 & 77.2 & 17.5 & \\
\hline lowST-lowPA & 6.4 & 59.6 & 34.0 & & 23.4 & & 22.2 & 69.4 & 8.3 & \\
\hline highST-lowPA & 6.3 & 54.2 & 39.6 & & 20.8 & & 16.7 & 72.2 & 11.1 & \\
\hline \multicolumn{11}{|l|}{ Screen time (hours/day) } \\
\hline$<2$ & 11.1 & 70.6 & 18.3 & \multirow{3}{*}{$<0.0001$} & 9.2 & \multirow{3}{*}{0.0004} & 11.9 & 76.9 & 11.2 & \multirow{3}{*}{0.6425} \\
\hline 2 to $<4$ & 9.2 & 61.7 & 29.1 & & 12.9 & & 13.2 & 74.2 & 12.7 & \\
\hline$\geq 4$ & 7.3 & 60.5 & 32.2 & & 18.2 & & 12.2 & 73.0 & 14.9 & \\
\hline \multicolumn{11}{|l|}{ Physical activity } \\
\hline low & 5.6 & 52.1 & 42.4 & \multirow{3}{*}{$<0.0001$} & 22.2 & \multirow{3}{*}{$<0.0001$} & 16.5 & 75.7 & 7.8 & \multirow{3}{*}{0.0072} \\
\hline moderate & 10.2 & 63.6 & 26.1 & & 13.8 & & 13.3 & 75.8 & 10.9 & \\
\hline high & 9.8 & 73.6 & 16.6 & & 6.2 & & 9.3 & 73.9 & 16.8 & \\
\hline
\end{tabular}

${ }^{1}$ Sample size may vary in variables due to missing data; ${ }^{2}$ gender-age-related-BMI categorized according to international standards [35] as follows: underweight BMI $<18.5 \mathrm{~kg} / \mathrm{m}^{2}$; normal weight BMI $=18.5$ to $24.9 \mathrm{~kg} / \mathrm{m}^{2}$; overweight BMI $\geq 25 \mathrm{~kg} / \mathrm{m}^{2} ;^{3}$ central obesity identified as waist-to-height ratio (WHtR) $\geq 0.5$ [36]; ${ }^{4}$ muscle strength identified as z-HGS (z-score

handgrip strength) as follows: lower $<-1 \mathrm{SD}$, normal -1 to $1 \mathrm{SD}$, higher $>1 \mathrm{SD}{ }^{5}$ significance level of $\mathrm{Chi}^{2}$ Pearson test. 
The associations of activity-inactivity patterns with overweight, central obesity, and muscle strength are shown in Figures 2-4. Teenagers with the most inactive pattern (highST-lowPA) had over four times higher chance of overweight $\left(\mathrm{OR}_{\mathrm{A}}: 4.11,95 \% \mathrm{CI} 1.92-8.81 ; p=0.0003\right)$, while those with the lowST-lowPA pattern had over three times higher chance of overweight $\left(\mathrm{OR}_{\mathrm{A}}: 3.28,95 \% \mathrm{CI}\right.$ $1.49-7.20 ; p=0.003)$. Teenagers with the highST-highPA pattern had over two times higher chance of overweight $\left(\mathrm{OR}_{\mathrm{A}}: 2.36,95 \% \mathrm{CI} 1.18-4.74 ; p=0.0153\right)$ in comparison with the reference active pattern (lowST-highPA) (Figure 2). Teenagers with ST $>2 \mathrm{~h} / \mathrm{d}$ had 1.8-2 times higher chance of being overweight $\left(\mathrm{OR}_{\mathrm{A}}: 1.81,95 \%\right.$ CI 1.37-4.74; $p=0.012$ and $\mathrm{OR}_{\mathrm{A}}: 2.00,95 \%$ CI 1.44-2.77; $\left.p<0.0001\right)$, while teenagers with high PA $\left(\mathrm{OR}_{\mathrm{A}}: 0.28,95 \% \mathrm{CI} 0.18-0.43 ; p<0.00001\right)$ (Figure 2$)$, with vigorous $\mathrm{PA}$ at school $\left(\mathrm{OR}_{\mathrm{A}}: 0.45,95 \% \mathrm{CI} 0.27-0.75 ; p=0.002\right)$, or with vigorous $\mathrm{PA}$ at leisure time $\left(\mathrm{OR}_{\mathrm{A}}: 0.48,95 \% \mathrm{CI}\right.$ $0.30-0.78 ; p=0.0026$ ), (Table S4) had approximately $52-72 \%$ lower chance of being overweight.

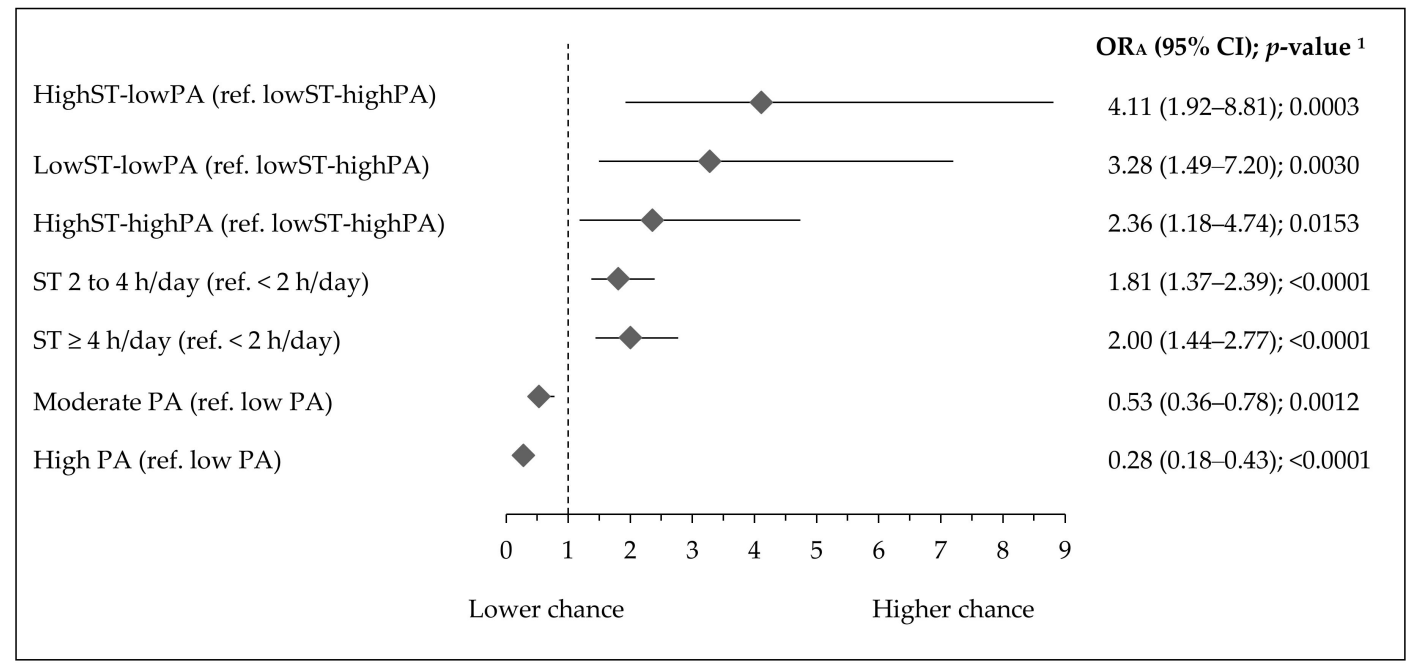

Figure 2. Association of activity-inactivity patterns, ST, and PA with overweight in Polish teenagers (ref. normal weight). Notes: ST—screen time; PA—physical activity; overweight and normal weight identified as gender-age-related-BMI according to international standards [35] as follows: overweight $\mathrm{BMI} \geq 25 \mathrm{~kg} / \mathrm{m}^{2}$, normal weight $\mathrm{BMI}=18.5$ to $24.9 \mathrm{~kg} / \mathrm{m}^{2} ; \mathrm{OR}_{\mathrm{A}}$ —odds ratio adjusted for gender, age (years), residence (categorical variable), Family Affluence Scale (points), and Nutrition Knowledge Score (points); $95 \% \mathrm{CI}$-confidence interval; ${ }^{1}$ Wald test significance level. 


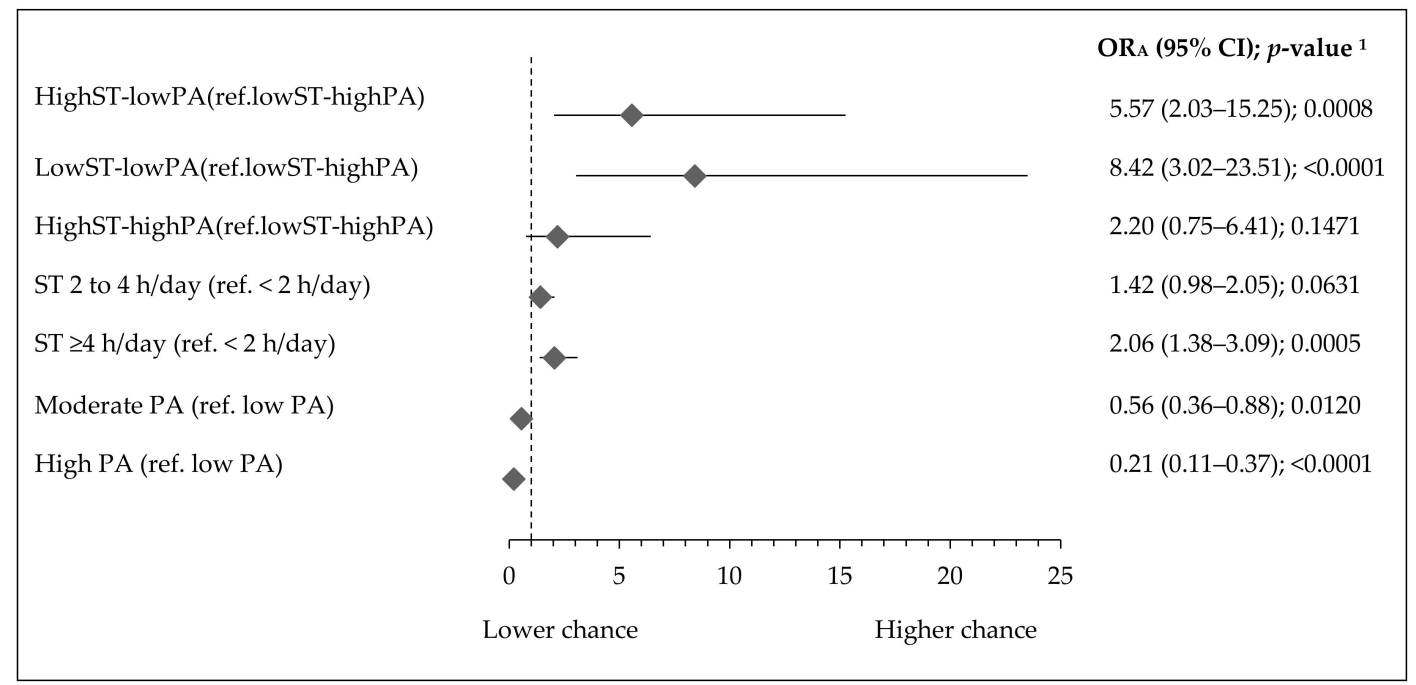

Figure 3. Association of activity-inactivity patterns, ST, and PA with central obesity in Polish teenagers (ref. lack of central obesity). Notes: ST—screen time; PA—physical activity; central obesity identified as waist-to-height ratio $\geq 0.5$; lack of central obesity identified as waist-to-height ratio $<0.5$ [36]; $\mathrm{OR}_{\mathrm{A}}$ 一odds ratio adjusted for gender, age (years), residence (categorical variable), Family Affluence Scale (points) and Nutrition Knowledge Score (points); 95\% CI—confidence interval; ${ }^{1}$ Wald test significance level.

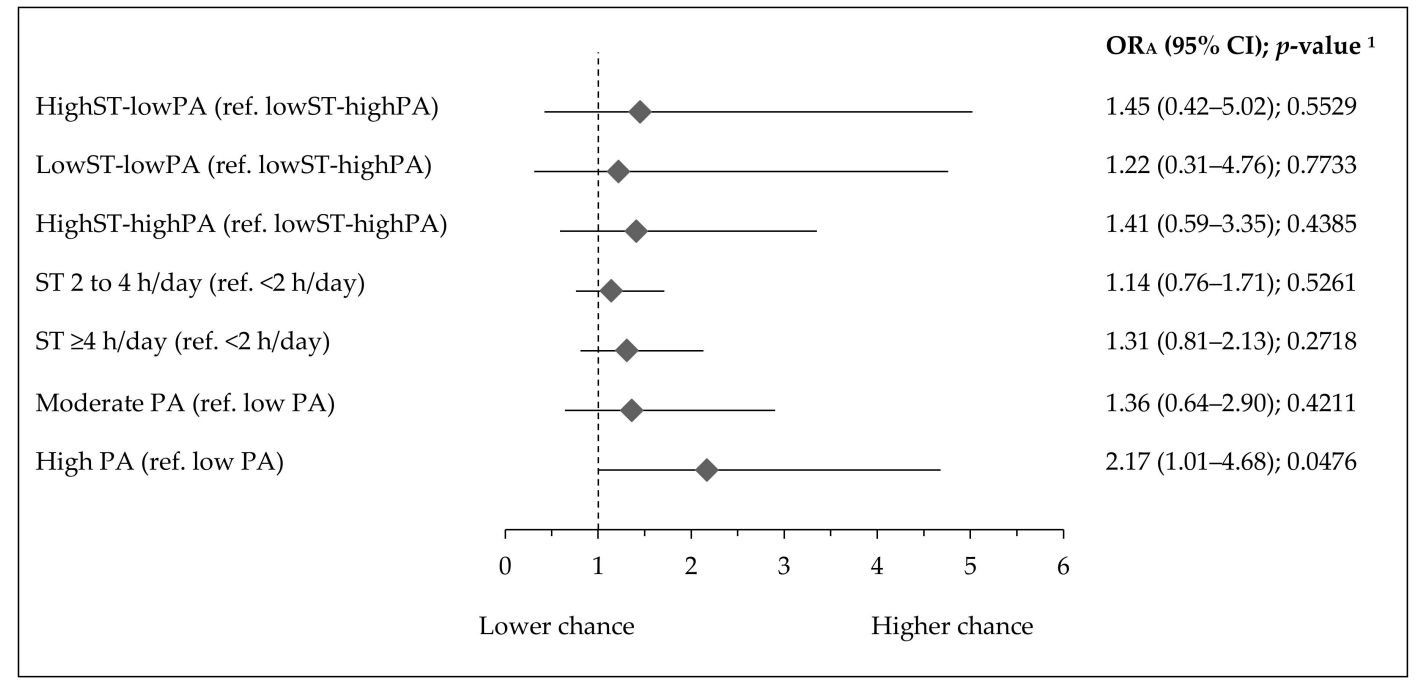

Figure 4. Association of activity-inactivity patterns, ST, and PA with higher muscle strength in Polish teenagers (ref. normal muscle strength). Notes: ST—screen time; PA—physical activity; higher and normal muscle strength identified as z-score handgrip strength as follows: higher $>1$ SD, normal-1 to 1 $\mathrm{SD} ; \mathrm{OR}_{\mathrm{A}}$-odds ratio adjusted for gender, age (years), residence (categorical variable), Family Affluence Scale (points) and Nutrition Knowledge Score (points); 95\% CI-confidence interval; ${ }^{1}$ Wald test significance level.

Teenagers with the lowST-lowPA pattern had over eight times higher chance of developing central obesity $\left(\mathrm{OR}_{\mathrm{A}}: 8.42,95 \%\right.$ CI 3.02-23.51; $\left.p<0.0001\right)$, while teenagers with a highST-lowPA pattern had over five times higher chance of central obesity $\left(\mathrm{OR}_{\mathrm{A}}: 5.57,95 \% \mathrm{CI} 2.03-15.25 ; p=0.0008\right)$ (Figure 3). No association between central obesity and the highST-highPA pattern was found. Teenagers with ST $\geq 4 \mathrm{~h}$ /day had two times higher chance of central obesity $\left(\mathrm{OR}_{\mathrm{A}}: 2.06,95 \% \mathrm{CI} 1.38-3.09 ; p=0.0005\right)$, while teenagers with high PA $\left(\mathrm{OR}_{\mathrm{A}}: 0.21,95 \%\right.$ CI $\left.0.11-0.37 ; p<0.0001\right)$ (Figure 3), with vigorous PA at school $\left(\mathrm{OR}_{\mathrm{A}}: 0.38,95 \% \mathrm{CI} 0.20-0.71 ; p=0.0023\right)$ or with vigorous PA at leisure time $\left(\mathrm{OR}_{\mathrm{A}}: 0.31,95 \% \mathrm{CI}\right.$ $0.18-0.51 ; p<0.00001$ ) (Table S4) had approximately $62-79 \%$ lower risk of central obesity. 
No association between activity-inactivity patterns with muscle strength was found (Figure 4). Teenagers with high PA had 2.2 times higher chance of having higher muscle strength $\left(\mathrm{OR}_{\mathrm{A}}: 2.17\right.$, $95 \%$ CI $1.01-4.68 ; p=0.0476$ ).

Socioeconomic and demographic factors associated with activity-inactivity patterns are presented in Figures 5-7. The adherence to the most inactive pattern (highST-lowPA) was positively associated with urban residence $\left(\mathrm{OR}_{\mathrm{A}}: 2.70,95 \%\right.$ CI 1.27-5.72; $\left.p=0.0092\right)$, while negatively with moderate FAS $\left(\mathrm{OR}_{\mathrm{A}}: 0.29,95 \%\right.$ CI $\left.0.14-0.60 ; p=0.0007\right)$ or high FAS $\left(\mathrm{OR}_{\mathrm{A}}: 0.18,95 \%\right.$ CI $\left.0.06-0.50 ; p=0.0011\right)$ (Figure 5). Girls had a higher adherence to the lowST-lowPA pattern $\left(\mathrm{OR}_{\mathrm{A}}: 2.01,95 \% \mathrm{CI} 1.04-3.92\right.$; $p=0.0382)$, while teenagers with moderate FAS $\left(\mathrm{OR}_{\mathrm{A}}: 0.43,95 \% \mathrm{CI} 0.21-0.88 ; p=0.0198\right)$ or high FAS ( $\left.\mathrm{OR}_{\mathrm{A}}: 0.11,95 \% \mathrm{CI} 0.03-0.37 ; p=0.0003\right)$ had lower adherence (Figure 6$)$. The adherence to the highST-highPA pattern was lower by $45 \%$ in girls $\left(\mathrm{OR}_{\mathrm{A}}: 0.55,95 \% \mathrm{CI} 0.31-0.97 ; p=0.0369\right)$ (Figure 7 ).

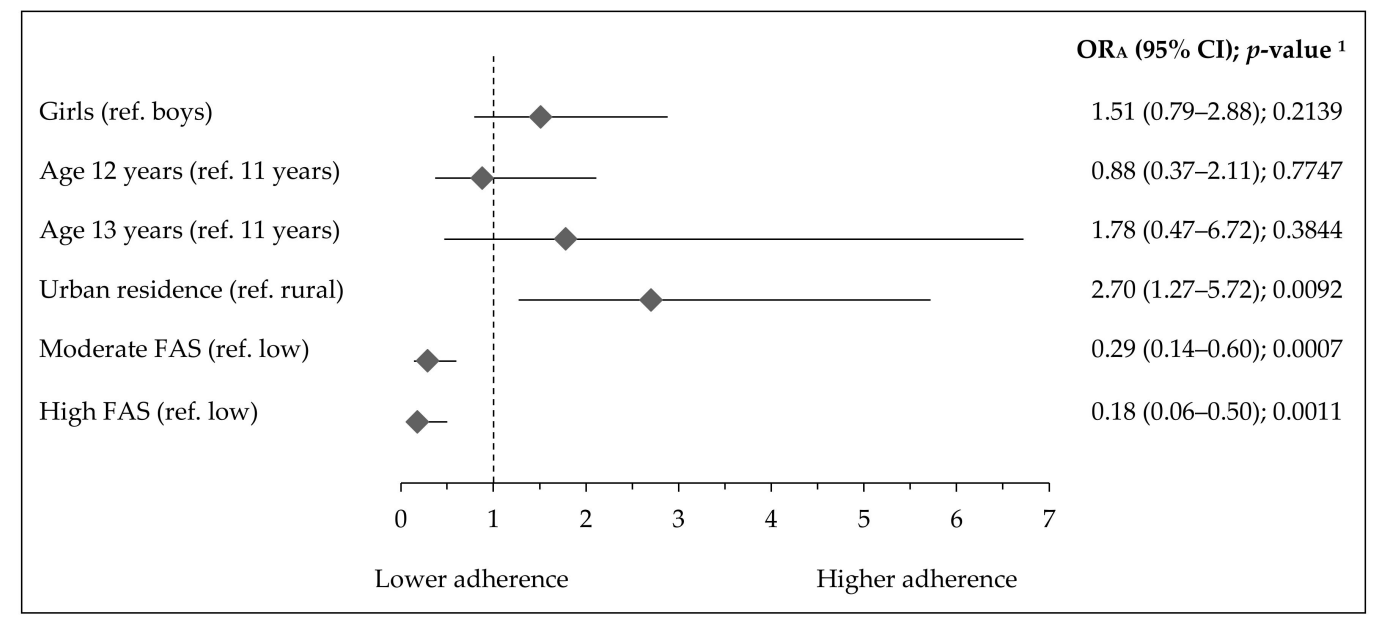

Figure 5. Factors associated with highST-lowPA pattern in Polish teenagers (ref. lowST-highPA pattern). Notes: ST—screen time; PA—physical activity; FAS—Family Affluence Scale; $\mathrm{OR}_{\mathrm{A}}$ —odds ratio adjusted for gender, age (years), residence (categorical variable), FAS (points) and Nutrition Knowledge Score (points) excluding the modelled variable from confounders set, respectively; 95\% CI-confidence interval; ${ }^{1}$ Wald test significance level.

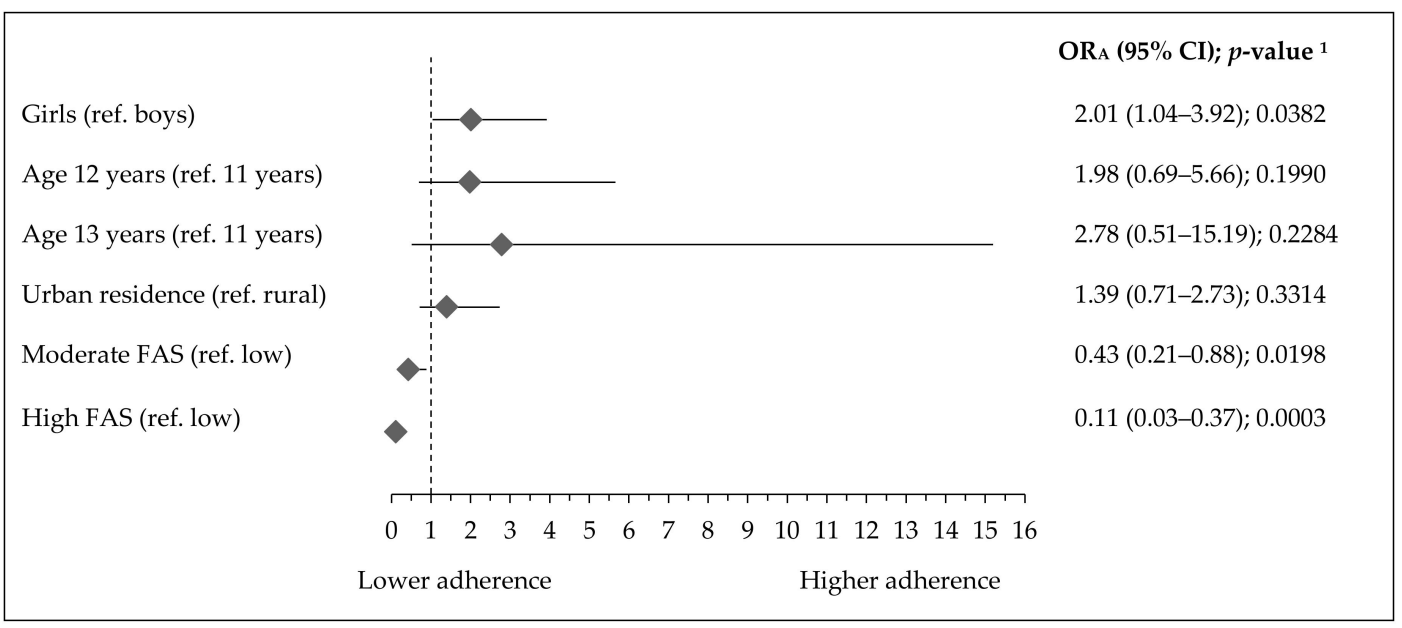

Figure 6. Factors associated with lowST-lowPA pattern in Polish teenagers (ref. lowST-highPA pattern). Notes: ST—screen time; PA—physical activity; FAS—Family Affluence Scale; $\mathrm{OR}_{\mathrm{A}}$ —odds ratio adjusted for gender, age (years), residence (categorical variable), FAS (points) and Nutrition Knowledge Score (points) excluding the modelled variable from confounders set, respectively; 95\% CI-confidence interval; ${ }^{1}$ Wald test significance level. 


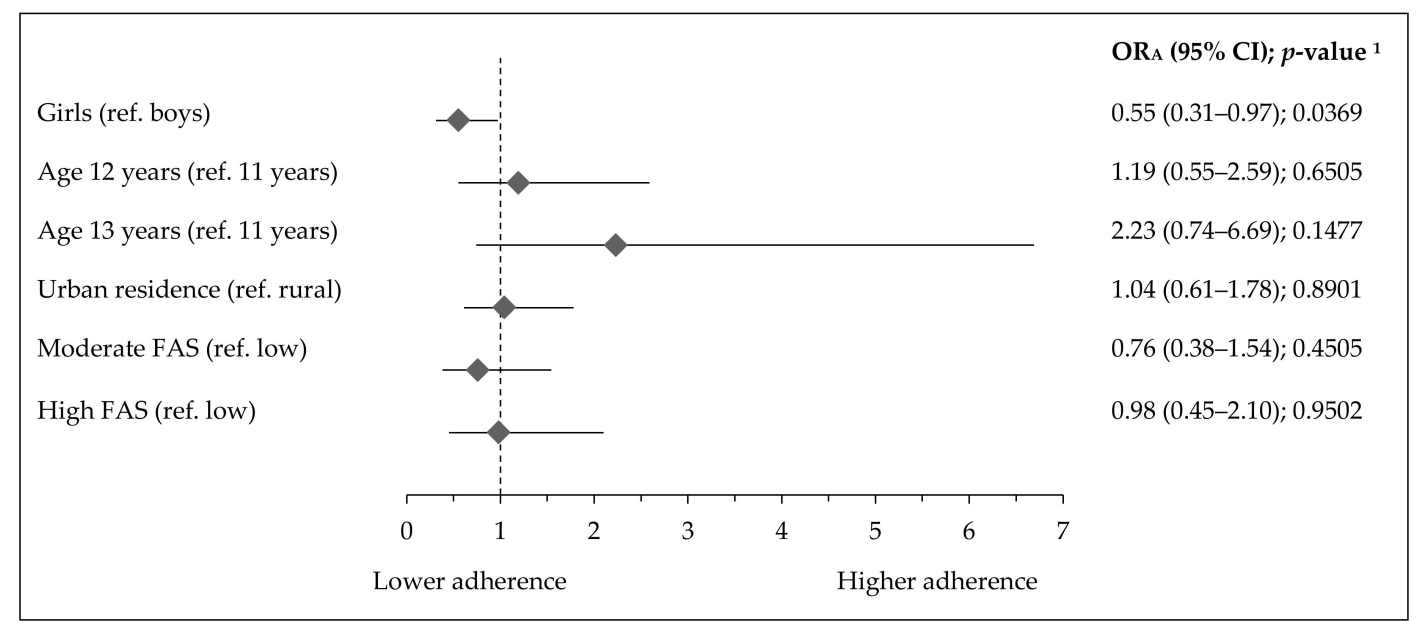

Figure 7. Factors associated with highST-highPA pattern in Polish teenagers (ref. lowST-highPA pattern). Notes: ST—screen time; PA—physical activity; FAS—Family Affluence Scale; $\mathrm{OR}_{\mathrm{A}}$ —odds ratio adjusted for gender, age (years), residence (categorical variable), FAS (points) and Nutrition Knowledge Score (points) excluding the modelled variable from confounders set, respectively; $95 \% \mathrm{CI}$-confidence interval; ${ }^{1}$ Wald test significance level.

The lower chance of high ST ( $\geq 4 \mathrm{~h} /$ day) belonged to girls $\left(\mathrm{OR}_{\mathrm{A}}: 0.62,95 \%\right.$ CI $\left.0.47-0.82 ; p=0.0008\right)$ and teenagers with moderate FAS $\left(\mathrm{OR}_{\mathrm{A}}: 0.70,95 \%\right.$ CI $\left.0.50-0.98 ; p=0.0351\right)$, while higher chance with urban residence $\left(\mathrm{OR}_{\mathrm{A}}: 1.45,95 \%\right.$ CI $\left.1.08-1.93 ; p=0.0122\right)$ (Table S5). Teenagers with high FAS had a higher chance of high PA in total, vigorous PA at school or PA at leisure time $\left(\mathrm{OR}_{\mathrm{A}}: 3.53\right.$, 95\% CI 1.97-6.31; $p<0.0001$, and $\mathrm{OR}_{\mathrm{A}}: 2.70,95 \%$ CI 1.38-5.31; $p=0.0038$, and $\mathrm{OR}_{\mathrm{A}}: 3.06,95 \% \mathrm{CI}$ $1.79-5.24 ; p<0.0001$, respectively). In turn, female gender or urban residence lowered the chance of high total PA $\left(\mathrm{OR}_{\mathrm{A}}: 0.67,95 \% \mathrm{CI} 0.46-0.99 ; p=0.043\right.$, and $\left.\mathrm{OR}_{\mathrm{A}}: 0.62,95 \% \mathrm{CI} 0.41-0.92 ; p=0.0171\right)$. Moreover, urban residence lowered the chance of vigorous $\mathrm{PA}$ at leisure time $\left(\mathrm{OR}_{\mathrm{A}}: 0.63,95 \% \mathrm{CI}\right.$ 0.43-0.92; $p=0.0174$ ) (Table S5).

A similar association between activity-inactivity patterns, ST, PA, and overweight, central obesity, and muscle strength (Table S6) and socioeconomic and demographic factors were found in crude models (Table S7). Those results are presented in Supplementary Materials.

\section{Discussion}

According to our knowledge, this study is the first study investigating the association of activity-inactivity patterns with obesity-related measures BMI and WHtR as well as with muscle strength in young adolescents living in Poland. The study revealed that the most active pattern, that combined the low screen time with high physical activity, was identified in almost $17 \%$ of teenagers. However, considering screen time or physical activity alone, over $40 \%$ of teenagers reported low screen time and over $30 \%$ reported high physical activity. This clearly shows that separate studies on screen time or physical activity level could also lead to overestimation. The current results confirmed the hypothesis that lifestyle behaviors of the majority of Polish teenagers can increase their obesity risk. It was found that, regardless of the time spent looking at a screen, low levels of physical activity were associated with higher chances of being overweight or having central obesity. Moreover, central obesity (assessed by WHtR) was more strongly associated with inactivity patterns (low physical activity, regardless of screen time), and no association was found with high screen time-high physical activity patterns. Higher muscle strength was associated only with high physical activity. Urban residence or lower family affluence increased adherence to the most inactive pattern. Girls had higher adherence to a pattern combining low physical activity with low time spent before a screen.

These findings indicate the need to change lifestyle behaviors in adolescents to reduce the prevalence of metabolic diseases in adulthood, often associated with excessive body weight. 
In previous studies integrative classification of high screen time and low physical activity [39] or moderate-to-vigorous physical activity and sedentary behavior [40] was used to examine their associations with health indicators. Results showed that adolescents with sedentary behaviors had higher odds of overweight and abdominal obesity [39] or higher cardiometabolic risk [40]. Cristi-Montero et al. [40] concluded that meeting the current physical activity recommendations and reducing time spent sedentary in European adolescents was beneficial for cardiometabolic health, which also depends on obesity. Sedentary behaviors are associated with serious physical health problems, primarily in the context of obesity [41]. Currently, new technologies favor a sedentary lifestyle and thus increase the obesity risk of adolescents. Despite knowledge of the increasing prevalence of obesity and the role of screen-based activities as a major contributor to the obesity epidemic, there is a lack of practical guidelines for parents, teachers, and practitioners to limit digital technologies and online activities in everyday life [41].

Our findings on strong associations between central obesity and inactivity patterns, and not with the high screen time-high physical activity pattern, extend knowledge about obesity risk factors in the developing population. The association between physical activity or screen time and obesity are more often investigated using body mass index (BMI) [42-44], although waist-to-height ratio (WHtR) may be a better marker of adiposity in children $[45,46]$. Central obesity more strongly correlates with metabolic risk factors and is a better predictor of cardiometabolic risk in children [47]. Comparing those results with general overweight assessed by BMI, central obesity was more strongly associated with inactivity patterns. This finding is not entirely consistent with the results of Engberg et al. who studied Finnish children aged 11 years. They analyzed the relationship between screen time and BMI and WHtR and reported similar associations of TV viewing and computer use with BMI and WHtR [48]. However, it is important to note that the current study concerned patterns composed of physical activity and time spent before a screen.

There was no association between muscle strength and activity-inactivity patterns. Higher muscle strength was only associated with high total physical activity or vigorous physical activity at school. In the current study, we used handgrip strength as an indirect measure of muscle strength. It should be noted that although handgrip is a measure of upper limb strength, it was previously found that it correlates well with other measures of upper and lower body strength [49], muscle mass, and bone mineral density in children and adolescents [49,50]. Muscle strength in teenagers is more often investigated concerning physical activity and a positive relationship between them has been reported [19]. Results of studies examining muscle strength and its association with screen time are limited and inconsistent, although inverse associations between viewing television and sedentary behavior and physical fitness have generally been reported [51].

The current findings highlight the crucial role of activity pattern promotion, including an increase in physical activity level in obesity prevention and higher muscle strength. Teenagers with high physical activity at school and at leisure time had a lower chance of being overweight and central obesity. Thus, according to the findings of the current study, meeting physical activity recommendations should be the primary public health strategy more than reducing screen time. Reducing only screen time may be insufficient to prevent adiposity because it may not increase the time spent on physical activity and, in consequence, the risk of overweight may increase [40,52]. To improve the current situation, it seems that the best place to implement programs related to nutrition and lifestyle could be in schools. School-based interventions, according to research, have the potential and effectiveness of programs by targeting a variety of health behaviors $[53,54]$. As indicated by Throuvala et al. [41] there is an urgent need for more integrated, health-promoting prevention programs in the school environment, targeting a change from sedentary to an active lifestyle.

In this study, it was hypothesized that inactivity patterns, would be associated with socio-demographics. The results indicated that girls had higher adherence than boys to the low screen time-low physical activity pattern but had lower adherence to the high screen time-high physical activity pattern. These results concerning lifestyle components and gender are in line with 
previously reported results that screen time and physical activity are gender-dependent. Although boys are more engaged in higher levels of screen time [55-59], they are also more positive about physical activity than girls [60]. Boys have more opportunities to be active in school, out of school and outdoors, and they are more encouraged to practice sports $[61,62]$ through a wider offer of sports activities. Furthermore, the gender differences are explained sociologically and are associated with the changing but still existent division of social roles in adult life [61]. Girls spend less time using screen devices, but are also less physically active than boys and are at higher risk of physical inactivity $[56,58,63-66]$. These findings confirm that girls should be specifically targeted for physical activity campaigns, both at school and in their leisure time.

Furthermore, the study found that teenagers with lower socioeconomic status had higher adherence to inactivity patterns (low screen time-low physical activity or high screen time-low physical activity). As other authors [67-69] have indicated, children from families with low socioeconomic status have a higher risk of unhealthier lifestyle, including more time spent watching TV. Family socioeconomic status plays a key role in teenagers' physical activity [70]. It has also been shown that teenagers from high-status families had better access to sports facilities, exercised more [69] and had better physical fitness [71]. These findings confirm that using public health policy to increase physical activity should also take into account socioeconomic determinants.

The current study also revealed that urban residence was strongly associated with the most inactive pattern in Polish teenagers. Findings by other researchers have been mixed. Some of them show $[72,73]$ that teenagers from urban areas had lower levels of physical activity, while others reported that rural adolescents are more exposed to sedentary behavior [74]. The differences may be due to national environmental factors, e.g., urbanization or annual average national temperature [75] or it may result from social awareness. In addition, the availability of public leisure spaces, such as squares, courts, skate parks, swimming pools and bike paths are important for increasing physical activity. In Poland, challenges include a lack of attractive sports activities in schools and school sports infrastructure (and access to it), as well as the low physical activity of children associated with the route to school [76]. Due to the growing percentage of obese teenagers, it seems important to create favorable conditions to increase physical activity for all children regardless of the place of residence or socioeconomic status and to increase accessibility to free public leisure spaces, especially outdoors.

\section{Strengths and Limitations}

The strengths of the present study include using activity-inactivity patterns concerning general overweight (BMI), central obesity (WHtR), and muscle strength in Polish teenagers. The current study measured the weight, height, waist circumference and handgrip strength and used two obesity-related outcomes to give a broader picture on examining associations. An important strength is the relatively large sample of teenagers from different regions of Poland. The sample size was large enough (above 1500) to determine statistically significant associations that are also meaningful in practice.

Although the sample was not randomly selected, it does widely reflect the sociodemographic status of Polish society, which the authors believe provides a good basis for the creation of such generalizations.

The limitations of the current study also need to be mentioned. First, the main limitation was using self-reported data on screen time and physical activity, although in other studies self-reporting has been found to offer satisfactory reliability in terms of health-related behaviors [77]. It was decided to use this form due to the larger sample size and the children's age. Moreover, the presence of qualified researchers while filling in the questionnaire allowed the teenagers to clarify any uncertainties. However, incorrect indication of individual categories may result in a non-differentiation error. Second, only television and computer time were considered screen time. Although television is still the dominant media for family time, there is increased exposure and accessibility to mobile screen media devices and active gaming among adolescents. This may also have the potential to increase moderate physical activity [57]. Future research should include evolving forms of non-sedentary games with motion controllers, which may also require body movements and affect the time spent actively. In this 
study, dietary patterns and food consumption (which also affect body weight) were not taken into account, which should also be considered a limitation. Finally, the cross-sectional design of the study precludes the investigation of casual relationships.

\section{Conclusions}

Inactivity patterns composed of low physical activity (regardless of time spent before a screen) were associated with a higher chance of overweight and central obesity, while no association with muscle strength was found. However, high physical activity, considered alone, in comparison with low physical activity, was negatively associated with general overweight and central obesity and was positively associated with muscle strength. From a public health perspective, implementing interventions promoting active patterns in 11-13-year-old teenagers is important for obesity prevention and enhancing physical fitness. These findings can be used by policymakers to develop guidelines and develop strategies to reduce inactivity for teenagers. Girls, particularly teenagers with urban residence or those with lower socioeconomic status, due to a combination of prolonged screen time with lower levels of physical activity, should be the population targeted by public health efforts to prevent obesity and improve youth well-being. For future research, these findings shed light on the importance of assessing the chance of obesity through an integrative classification of physical activity and time spent before a screen.

Supplementary Materials: The following are available online at http://www.mdpi.com/1660-4601/17/21/7842/s1, Table S1. Distributions (\%) of variables by physical activity at school or at leisure time ( $\mathrm{N}=1567)$; Table S2. Distributions (\% of the sample) of physical activity by screen time; Table S3. Distributions (\%) of BMI category, central obesity and muscle strength by physical activity at school or at leisure time; Table S4. Association between physical activity at school, physical activity at leisure time and overweight, central obesity or muscle strength $\left(\mathrm{OR}_{\mathrm{A}}\right)$; Table S5. Association between physical activity at school, physical activity at leisure time and socioeconomics or demographics $\left(\mathrm{OR}_{\mathrm{A}}\right)$; Table S6. Association between activity-inactivity patterns, ST, PA, and overweight, central obesity or muscle strength (crude OR); Table S7. Association between activity-inactivity patterns, ST, PA, and socioeconomics or demographics (crude OR).

Author Contributions: J.H., L.W. and J.K. were responsible for the conception and design of the main study and this paper. J.K. was responsible for the data cleaning and statistical analysis for the main study and this paper. M.G., J.H., L.W. and J.K. were responsible for data interpretation for this paper. J.H. was involved in the funding acquisition for the project and managing of the project. J.H., M.G., J.K., E.K., M.T., J.C. and M.B. were responsible for data collection of the main study. M.G. was responsible for data visualization. M.G. and J.H. were responsible for writing the original draft of the manuscript. J.H. and L.W. were responsible for revising the manuscript critically for important intellectual content. The manuscript has been revised by all co-authors. All authors have read and agreed to the published version of the manuscript.

Funding: The study was financially supported by the Carrefour Foundation (Agreement ABC No. 1/2014; Agreement $A B C$ No. 2/2016) and each scientific center from sources of the Polish Ministry of Sciences and Higher Education.

Acknowledgments: The authors would like to thank the parents, school staff and the participants who made this study possible.

Conflicts of Interest: The authors declare no conflict of interest. The funders had no role in the design of the study; in the collection, analyses, or interpretation of data; in the writing of the manuscript, or in the decision to publish the results.

\section{Abbreviations}

$\begin{array}{ll}\text { 95\% CI } & \text { Confidence Intervals } \\ \text { BMI } & \text { Body Mass Index } \\ \text { FAS } & \text { Family Affluence Scale } \\ \text { HGS } & \text { Hand Grip Strength } \\ \text { ORs } & \text { Odds Ratios } \\ \text { PA } & \text { Physical Activity } \\ \text { SD } & \text { Standard Deviation } \\ \text { ST } & \text { Screen Time } \\ \text { WC } & \text { Waist Circumference } \\ \text { WHtR } & \text { Waist-to-Height Ratio }\end{array}$




\section{References}

1. Abarca-Gómez, L.; Abdeen, Z.A.; Hamid, Z.A.; Abu-Rmeileh, N.M.; Acosta-Cazares, B.; Acuin, C.; Adams, R.J.; Aekplakorn, W.; Afsana, K.; Aguilar-Salinas, C.A.; et al. Worldwide trends in body-mass index, underweight, overweight, and obesity from 1975 to 2016: A pooled analysis of 2416 population-based measurement studies in 128.9 million children, adolescents, and adults. Lancet 2017, 390, 2627-2642. [CrossRef]

2. OECD Obesity Update 2017. Available online: http://www.oecd.org/health/obesity-update.htm (accessed on 5 February 2020).

3. Suder, A.; Gomula, A.; Koziel, S. Central overweight and obesity in Polish schoolchildren aged 7-18 years: Secular changes of waist circumference between 1966 and 2012. Eur. J. Pediatr. 2017, 176, 909-916. [CrossRef] [PubMed]

4. Schwarzfischer, P.; Gruszfeld, D.; Socha, P.; Luque, V.; Closa-Monasterolo, R.; Rousseaux, D.; Moretti, M.; Mariani, B.; Verduci, E.; Koletzko, B.; et al. Longitudinal analysis of physical activity, sedentary behaviour and anthropometric measures from ages 6 to 11 years. Int. J. Behav. Nutr. Phys. Act. 2018, 15, 126. [CrossRef]

5. Serrano-Sanchez, J.A.; Martí-Trujillo, S.; Lera-Navarro, A.; Dorado-García, C.; González-Henríquez, J.J.; Sanchís-Moysi, J. Associations between Screen Time and Physical Activity among Spanish Adolescents. PLoS ONE 2011, 6, e24453. [CrossRef] [PubMed]

6. Moschonis, G.; Kaliora, A.C.; Karatzi, K.; Michaletos, A.; Lambrinou, C.-P.; Karachaliou, A.K.; Chrousos, G.P.; Lionis, C.; Manios, Y. Perinatal, sociodemographic and lifestyle correlates of increased total and visceral fat mass levels in schoolchildren in Greece: The Healthy Growth Study. Public Health Nutr. 2017, 20, 660-670. [CrossRef]

7. Lajous, M.; Chavarro, J.; Peterson, K.E.; Hernández-Prado, B.; Cruz-Valdéz, A.; Hernández-Ávila, M.; Lazcano-Ponce, E. Screen time and adiposity in adolescents in Mexico. Public Health Nutr. 2009, 12, 1938-1945. [CrossRef]

8. Epstein, L.H.; Roemmich, J.N.; Robinson, J.L.; Paluch, R.A.; Winiewicz, D.D.; Fuerch, J.H.; Robinson, T.N. A Randomized Trial of the Effects of Reducing Television Viewing and Computer Use on Body Mass Index in Young Children. Arch. Pediatr. Adolesc. Med. 2008, 162, 239. [CrossRef]

9. Fletcher, E.A.; McNaughton, S.A.; Crawford, D.; Cleland, V.; Della Gatta, J.; Hatt, J.; Dollman, J.; Timperio, A. Associations between sedentary behaviours and dietary intakes among adolescents. Public Health Nutr. 2018, 21, 1115-1122. [CrossRef]

10. Pearson, N.; Griffiths, P.; Biddle, S.J.; Johnston, J.P.; McGeorge, S.; Haycraft, E. Clustering and correlates of screen-time and eating behaviours among young adolescents. BMC Public Health 2017, 17, 533. [CrossRef]

11. Abbade, E.B.; Dewes, H. Behavioral and societal drivers of an obesogenic environment worldwide. Nutr. Food Sci. 2015, 45, 229-241. [CrossRef]

12. Katzmarzyk, P.T.; Church, T.S.; Craig, C.L.; Bouchard, C. Sitting Time and Mortality from All Causes, Cardiovascular Disease, and Cancer. Med. Sci. Sports Exerc. 2009, 41, 998-1005. [CrossRef]

13. Hamilton, M.T.; Healy, G.N.; Dunstan, D.W.; Zderic, T.W.; Owen, N. Too little exercise and too much sitting: Inactivity physiology and the need for new recommendations on sedentary behavior. Curr. Cardio Risk. Rep. 2008, 2, 292-298. [CrossRef] [PubMed]

14. McManus, A.M.; Mellecker, R.R. Physical activity and obese children. J. Sport Health Sci. 2012, 1, 141-148. [CrossRef]

15. Głąbska, D.; Guzek, D.; Mellová, B.; Zadka, K.; Żywczyk, K.; Gutkowska, K. The National After-School Athletics Program Participation as a Tool to Reduce the Risk of Obesity in Adolescents after One Year of Intervention: A Nationwide Study. Int. J. Environ. Res. Public Health 2019, 16, 405. [CrossRef] [PubMed]

16. Iannotti, R.J.; Kogan, M.D.; Janssen, I.; Boyce, W.F. Patterns of Adolescent Physical Activity, Screen-Based Media Use, and Positive and Negative Health Indicators in the U.S. and Canada. J. Adolesc. Health 2009, 44, 493-499. [CrossRef] [PubMed]

17. Hallal, P.C.; Andersen, L.B.; Bull, F.C.; Guthold, R.; Haskell, W.; Ekelund, U. Global physical activity levels: Surveillance progress, pitfalls, and prospects. Lancet 2012, 380, 247-257. [CrossRef]

18. Henriksson, H.; Henriksson, P.; Tynelius, P.; Ekstedt, M.; Berglind, D.; Labayen, I.; Ruiz, J.R.; Lavie, C.J.; Ortega, F.B. Cardiorespiratory fitness, muscular strength, and obesity in adolescence and later chronic disability due to cardiovascular disease: A cohort study of 1 million men. Eur. Heart J. 2020, 41, 1503-1510. [CrossRef] 
19. Ng, A.K.; Hairi, N.N.; Jalaludin, M.Y.; Majid, H.A. Dietary intake, physical activity and muscle strength among adolescents: The Malaysian Health and Adolescents Longitudinal Research Team (MyHeART) study. BMJ Open 2019, 9, e026275. [CrossRef]

20. Martínez-Gómez, D.; Welk, G.J.; Puertollano, M.A.; del-Campo, J.; Moya, J.M.; Marcos, A.; Veiga, O.L.; AFINOS Study Group. Associations of physical activity with muscular fitness in adolescents: Physical activity and muscular fitness in adolescents. Scand. J. Med. Sci. Sports 2011, 21, 310-317. [CrossRef]

21. Jiménez-Pavón, D.; Fernández-Vázquez, A.; Alexy, U.; Pedrero, R.; Cuenca-García, M.; Polito, A.; Vanhelst, J.; Manios, Y.; Kafatos, A.; Molnar, D.; et al. Association of objectively measured physical activity with body components in European adolescents. BMC Public Health 2013, 13, 667. [CrossRef]

22. WHO. Global Recommendations on Physical Activity for Health; World Health Organization: Genève, Switzerland, 2010; ISBN 978-92-4-159997-9.

23. Pyramid of Healthy Nutrition and Physical Activity for Children. Available online: http://www.izz.waw.pl/ zasady-prawidowego-ywienia (accessed on 18 April 2020). (In Polish)

24. American Academy of Pediatrics. Committee on Public Education. American Academy of Pediatrics: Children, adolescents, and television. Pediatrics 2001, 107, 423-426. [CrossRef] [PubMed]

25. Pearson, N.; Braithwaite, R.E.; Biddle, S.J.H.; van Sluijs, E.M.F.; Atkin, A.J. Associations between sedentary behaviour and physical activity in children and adolescents: A meta-analysis: Active and sedentary behaviours in youth. Obes. Rev. 2014, 15, 666-675. [CrossRef] [PubMed]

26. Hamulka, J.; Wadolowska, L.; Hoffmann, M.; Kowalkowska, J.; Gutkowska, K. Effect of an Education Program on Nutrition Knowledge, Attitudes toward Nutrition, Diet Quality, Lifestyle, and Body Composition in Polish Teenagers. The ABC of Healthy Eating Project: Design, Protocol, and Methodology. Nutrients 2018, 10, 1439. [CrossRef] [PubMed]

27. Wadolowska, L.; Hamulka, J.; Kowalkowska, J.; Ulewicz, N.; Gornicka, M.; Jeruszka-Bielak, M.; Kostecka, M.; Wawrzyniak, A. Skipping Breakfast and a Meal at School: Its Correlates in Adiposity Context. Report from the ABC of Healthy Eating Study of Polish Teenagers. Nutrients 2019, 11, 1563. [CrossRef]

28. Wadolowska, L.; Hamulka, J.; Kowalkowska, J.; Kostecka, M.; Wadolowska, K.; Biezanowska-Kopec, R.; Czarniecka-Skubina, E.; Kozirok, W.; Piotrowska, A. Prudent-Active and Fast-Food-Sedentary Dietary-Lifestyle Patterns: The Association with Adiposity, Nutrition Knowledge and Sociodemographic Factors in Polish Teenagers-The ABC of Healthy Eating Project. Nutrients 2018, 10, 1988. [CrossRef]

29. Kowalkowska, J.; Wadolowska, L.; Hamulka, J.; Wojtas, N.; Czlapka-Matyasik, M.; Kozirok, W.; Bronkowska, M.; Sadowska, J.; Naliwajko, S.; Dziaduch, I.; et al. Reproducibility of a Short-Form, Multicomponent Dietary Questionnaire to Assess Food Frequency Consumption, Nutrition Knowledge, and Lifestyle (SF-FFQ4PolishChildren) in Polish Children and Adolescents. Nutrients 2019, 11, 2929. [CrossRef]

30. Council on Communications and Media Media Use in School-Aged Children and Adolescents. Pediatrics 2016, 138, e20162592. [CrossRef]

31. Guram, S.; Heinz, P. Media use in children: American Academy of Pediatrics recommendations 2016. Arch. Dis. Child. Edu. Pract. 2018, 103, 99-101. [CrossRef]

32. Ortega, F.B.; Cadenas-Sanchez, C.; Lee, D.; Ruiz, J.R.; Blair, S.N.; Sui, X. Fitness and Fatness as Health Markers through the Lifespan: An Overview of Current Knowledge. Prog. Prev. Med. 2018, 3, e0013. [CrossRef]

33. Australian 24-Hour Movement Guidelines for Children and Young People (5-17 Years) —An Integration of Physical Activity, Sedentary Behaviour and Sleep. Available online: https://www1.health.gov.au/internet/ main/publishing.nsf/Content/health-24-hours-phys-act-guidelines (accessed on 10 December 2019).

34. International Society for the Advancement of Kinanthropometry (ISAK). International Standards for Anthropometric Assessment; International Society for the Advancement of Kinanthropometry: Potchefstroom, South Africa, 2001.

35. Cole, T.J.; Lobstein, T. Extended international (IOTF) body mass index cut-offs for thinness, overweight and obesity: Extended international BMI cut-offs. Pediatric Obes. 2012, 7, 284-294. [CrossRef]

36. Ashwell, M.; Gunn, P.; Gibson, S. Waist-to-height ratio is a better screening tool than waist circumference and BMI for adult cardiometabolic risk factors: Systematic review and meta-analysis: Waist-to-height ratio as a screening tool. Obes. Rev. 2012, 13, 275-286. [CrossRef] [PubMed]

37. Mazur, J. Family Affluence Scale-Validation study and suggested modification. Hygeia Public Health 2013, 48, 211-217. 
38. Whati, L.H.; Senekal, M.; Steyn, N.P.; Nel, J.H.; Lombard, C.; Norris, S. Development of a reliable and valid nutritional knowledge questionnaire for urban South African adolescents. Nutrition 2005, 21, 76-85. [CrossRef] [PubMed]

39. Heshmat, R.; Qorbani, M.; Shahr Babaki, A.E.; Djalalinia, S.; Ataei-Jafari, A.; Motlagh, M.E.; Ardalan, G.; Arefirad, T.; Rezaei, F.; Asayesh, H.; et al. Joint Association of Screen Time and Physical Activity with Cardiometabolic Risk Factors in a National Sample of Iranian Adolescents: The CASPIANIII Study. PLoS ONE 2016, 11, e0154502. [CrossRef] [PubMed]

40. Cristi-Montero, C.; Chillón, P.; Labayen, I.; Casajus, J.A.; Gonzalez-Gross, M.; Vanhelst, J.; Manios, Y.; Moreno, L.A.; Ortega, F.B.; Ruiz, J.R. Cardiometabolic risk through an integrative classification combining physical activity and sedentary behavior in European adolescents: HELENA study. J. Sport Health Sci. 2019, 8, 55-62. [CrossRef]

41. Throuvala, M.A.; Griffiths, M.D.; Rennoldson, M.; Kuss, D.J. The Role of Recreational Online Activities in School-Based Screen Time Sedentary Behaviour Interventions for Adolescents: A Systematic and Critical Literature Review. Int. J. Ment. Health Addict. 2020. [CrossRef]

42. Biddle, S.J.H.; García Bengoechea, E.; Wiesner, G. Sedentary behaviour and adiposity in youth: A systematic review of reviews and analysis of causality. Int. J. Behav. Nutr. Phys. Act. 2017, 14, 43. [CrossRef] [PubMed]

43. Yan, H.; Zhang, R.; Oniffrey, T.; Chen, G.; Wang, Y.; Wu, Y.; Zhang, X.; Wang, Q.; Ma, L.; Li, R.; et al. Associations among Screen Time and Unhealthy Behaviors, Academic Performance, and Well-Being in Chinese Adolescents. Int. J. Environ. Res. Public Health 2017, 14, 596. [CrossRef]

44. Xu, F.; Adams, S.K.; Cohen, S.A.; Earp, J.E.; Greaney, M.L. Relationship between Physical Activity, Screen Time, and Sleep Quantity and Quality in US Adolescents Aged 16-19. Int. J. Environ. Res. Public Health 2019, 16, 1524. [CrossRef]

45. Brambilla, P.; Bedogni, G.; Heo, M.; Pietrobelli, A. Waist circumference-to-height ratio predicts adiposity better than body mass index in children and adolescents. Int. J. Obes. 2013, 37, 943-946. [CrossRef]

46. Lo, K.; Wong, M.; Khalechelvam, P.; Tam, W. Waist-to-height ratio, body mass index and waist circumference for screening paediatric cardio-metabolic risk factors: A meta-analysis: Screening cardio-metabolic risk factors. Obes. Rev. 2016, 17, 1258-1275. [CrossRef] [PubMed]

47. Savva, S.; Tornaritis, M.; Savva, M.; Kourides, Y.; Panagi, A.; Silikiotou, N.; Georgiou, C.; Kafatos, A. Waist circumference and waist-to-height ratio are better predictors of cardiovascular disease risk factors in children than body mass index. Int. J. Obes. 2000, 24, 1453-1458. [CrossRef] [PubMed]

48. Engberg, E.; Figueiredo, R.A.O.; Rounge, T.B.; Weiderpass, E.; Viljakainen, H. Heavy screen users are the heaviest among 10,000 children. Sci. Rep. 2019, 9, 11158. [CrossRef] [PubMed]

49. Milliken, L.A.; Faigenbaum, A.D.; Loud, R.L.; Westcott, W.L. Correlates of Upper and Lower Body Muscular Strength in Children. J. Strength Cond. Res. 2008, 22, 1339-1346. [CrossRef] [PubMed]

50. Chan, D.C.C.; Lee, W.T.K.; Lo, D.H.S.; Leung, J.C.S.; Kwok, A.W.L.; Leung, P.C. Relationship between grip strength and bone mineral density in healthy Hong Kong adolescents. Osteoporos Int. 2008, 19, 1485-1495. [CrossRef] [PubMed]

51. Edelson, L.R.; Mathias, K.C.; Fulgoni, V.L.; Karagounis, L.G. Screen-based sedentary behavior and associations with functional strength in 6-15 year-old children in the United States. BMC Public Health 2015, 16, 116. [CrossRef] [PubMed]

52. Kardefelt-Winther, D. How Does the Time Children Spend Using Digital Technology Impact Their Mental Well-Being, Social Relationships and Physical Activity? An Evidence-Focused Literature Review. Available online: https://www.unicefirc.org/publications/pdf/Children-digital-technology-wellbeing.pdf (accessed on 23 April 2020).

53. Hale, D.R.; Fitzgerald-Yau, N.; Viner, R.M. A Systematic Review of Effective Interventions for Reducing Multiple Health Risk Behaviors in Adolescence. Am. J. Public Health 2014, 104, e19-e41. [CrossRef]

54. van Grieken, A.; Ezendam, N.P.; Paulis, W.D.; van der Wouden, J.C.; Raat, H. Primary prevention of overweight in children and adolescents: A meta-analysis of the effectiveness of interventions aiming to decrease sedentary behaviour. Int. J. Behav Nutr. Phys. Act. 2012, 9, 61. [CrossRef]

55. Pujadas Botey, A.; Bayrampour, H.; Carson, V.; Vinturache, A.; Tough, S. Adherence to Canadian physical activity and sedentary behaviour guidelines among children 2 to 13 years of age. Prev. Med. Rep. 2016, 3, 14-20. [CrossRef] 
56. Garcia-Continente, X.; Perez-Gimenez, A.; Espelt, A.; Nebot Adell, M. Factors associated with media use among adolescents: A multilevel approach. Eur. J. Public Health 2013, 24. [CrossRef]

57. Wethington, H.; Sherry, B.; Park, S.; Blanck, H.M.; Fulton, J.E. Active Screen Time Among, U.S. Youth Aged 9-18 Years, 2009. Games Health J. 2013, 2, 362-368. [CrossRef]

58. Sirard, J.R.; Bruening, M.; Wall, M.M.; Eisenberg, M.E.; Kim, S.K.; Neumark-Sztainer, D. Physical Activity and Screen Time in Adolescents and Their Friends. Am. J. Prev Med. 2013, 44, 48-55. [CrossRef]

59. Finne, E.; Bucksch, J.; Lampert, T.; Kolip, P. Physical activity and screen-based media use: Cross-sectional associations with health-related quality of life and the role of body satisfaction in a representative sample of German adolescents. Health Psychol. Behav. Med. 2013, 1, 15-30. [CrossRef] [PubMed]

60. Brophy, S.; Crowley, A.; Mistry, R.; Hill, R.; Choudhury, S.; Thomas, N.E.; Rapport, F. Recommendations to improve physical activity among teenagers-A qualitative study with ethnic minority and European teenagers. BMC Public Health 2011, 11, 412. [CrossRef]

61. Marques, A.; da Costa, F.C. Levels of Physical Activity of Urban Adolescents According to Age and Gender. Int. J. Sports Sci. 2013, 3, 23-27. [CrossRef]

62. Larson, L.R.; Szczytko, R.; Bowers, E.P.; Stephens, L.E.; Stevenson, K.T.; Floyd, M.F. Outdoor Time, Screen Time, and Connection to Nature: Troubling Trends Among Rural Youth? Environ. Behav. 2018, 51, 966-991. [CrossRef]

63. Arundell, L.; Salmon, J.; Koorts, H.; Contardo Ayala, A.M.; Timperio, A. Exploring when and how adolescents sit: Cross-sectional analysis of activPAL-measured patterns of daily sitting time, bouts and breaks. BMC Public Health 2019, 19, 653. [CrossRef] [PubMed]

64. Haidar, A.; Ranjit, N.; Archer, N.; Hoelscher, D.M. Parental and peer social support is associated with healthier physical activity behaviours in adolescents: A cross-sectional analysis of Texas School Physical Activity and Nutrition (TX SPAN) data. BMC Public Health 2019, 19, 640. [CrossRef]

65. De Lucena, J.M.S.; Cheng, L.A.; Cavalcante, T.L.M.; da Silva, V.A.; de Farias Júnior, J.C. Prevalência de tempo excessivo de tela e fatores associados em adolescentes. Rev. Paul. De Pediatr. 2015, 33, 407-414. [CrossRef] [PubMed]

66. Melkevik, O.; Torsheim, T.; Iannotti, R.J.; Wold, B. Is spending time in screen-based sedentary behaviours associated with less physical activity: A cross national investigation. Int. J. Behav. Nutr. Phys. Act. 2010, 7, 46. [CrossRef] [PubMed]

67. Syed, N.; Schneider, M. Determining If Differences in Socioeconomic Status Are Associated With Screen Time Behavior and Physical Activity Levels. J. Nutr. Educ. Behav. 2016, 48, S58-S59. [CrossRef]

68. Hankonen, N.; Heino, M.T.J.; Kujala, E.; Hynynen, S.-T.; Absetz, P.; Araújo-Soares, V.; Borodulin, K.; Haukkala, A. What explains the socioeconomic status gap in activity? Educational differences in determinants of physical activity and screentime. BMC Public Health 2017, 17, 144. [CrossRef]

69. Drenowatz, C.; Eisenmann, J.C.; Pfeiffer, K.A.; Welk, G.; Heelan, K.; Gentile, D.; Walsh, D. Influence of socio-economic status on habitual physical activity and sedentary behavior in 8- to 11-year old children. BMC Public Health 2010, 10, 214. [CrossRef] [PubMed]

70. Lisinskiene, A.; Juskeliene, V. Links between Adolescents' Engagement in Physical Activity and Their Attachment to Mothers, Fathers, and Peers. Int. J. Environ. Res. Public Health 2019, 16, 866. [CrossRef] [PubMed]

71. Yi, X.; Fu, Y.; Burns, R.D.; Bai, Y.; Zhang, P. Body mass index and physical fitness among Chinese adolescents from Shandong Province: A cross-sectional study. BMC Public Health 2019, 19, 81. [CrossRef] [PubMed]

72. Regis, M.F.; Oliveira, L.M.F.T.d.; Santos, A.R.M.d.; Leonidio, A.d.C.R.; Diniz, P.R.B.; Freitas, C.M.S.M.d. Urban versus rural lifestyle in adolescents: Associations between environment, physical activity levels and sedentary behavior. Einstein (São Paulo) 2016, 14, 461-467. [CrossRef]

73. Neto, A.F.; Eto, F.N.; Silva Pereira, T.S.; Carletti, L.; Bisi Molina, M.d.C. Active and sedentary behaviours in children aged 7 to 10 years old: The urban and rural contexts, Brazil. BMC Public Health 2014, 14, 1174. [CrossRef]

74. Machado-Rodrigues, A.M.; Coelho-E.-Silva, M.J.; Mota, J.; Padez, C.; Martins, R.A.; Cumming, S.P.; Riddoch, C.; Malina, R.M. Urban-rural contrasts in fitness, physical activity, and sedentary behaviour in adolescents. Health Promot. Inter. 2014, 29, 118-129. [CrossRef]

75. Weinberg, D.; Stevens, G.W.J.M.; Bucksch, J.; Inchley, J.; de Looze, M. Do country-level environmental factors explain cross-national variation in adolescent physical activity? A multilevel study in 29 European countries. BMC Public Health 2019, 19, 680. [CrossRef] 
76. Fijałkowska, A. Current Evaluation of the Physical Activity Level Children and Teenagers Aged 3-19 Years in Poland; Ministry of Sport and Tourism: Warsaw, Poland, 2018.

77. Del Boca, F.K.; Noll, J.A. Truth or consequences: The validity of self-report data in health services research on addictions. Addiction 2000, 95, 347-360. [CrossRef]

Publisher's Note: MDPI stays neutral with regard to jurisdictional claims in published maps and institutional affiliations.

(C) 2020 by the authors. Licensee MDPI, Basel, Switzerland. This article is an open access article distributed under the terms and conditions of the Creative Commons Attribution (CC BY) license (http://creativecommons.org/licenses/by/4.0/). 